\title{
Fungal Colonization
}

National Cancer Institute

\section{Source}

National Cancer Institute. Fungal Colonization. NCI Thesaurus. Code C82980.

Collection of fungal organisms in an anatomic site or medical device. 